\title{
Phytoprotection
}

\section{Regulation of Microbial Organisms in Australia - A Technical Overview}

\section{Graeme Barden}

Volume 79, numéro 4, 1998

OECD Workshop - Sustainable Pest Management, Safe Utilization of New Organisms in Biological Control. Montréal, Québec, Canada. September 27-30, 1998.

Atelier de l'OCDE - Gestion durable des ennemis des cultures, Utilisation sécuritaire de nouveaux organismes de lutte biologique. Montréal, Québec, Canada. 27-30 Septembre 1998.

URI : https://id.erudit.org/iderudit/706150ar

DOI : https://doi.org/10.7202/706150ar

Aller au sommaire du numéro

\section{Éditeur(s)}

Société de protection des plantes du Québec (SPPQ)l

ISSN

0031-9511 (imprimé)

1710-1603 (numérique)

Découvrir la revue

Citer cet article

Barden, G. (1998). Regulation of Microbial Organisms in Australia - A Technical Overview. Phytoprotection, 79(4), 14-21. https://doi.org/10.7202/706150ar

\section{Résumé de l'article}

The National Registration Authority for Agricultural and Veterinary Chemicals (NRA) is the regulatory body responsible for the coordinated registration, regulation and review of agricultural and veterinary (agvet) chemicals up to and including the point of retail sale. This role is defined by the Agvet Code, 1994. Each of Australia's eight states and territories retains its own jurisdictional controls over the use of agricultural and veterinary products.

The NRA may issue permits to exercise control over research agricultural and veterinary (agvet) chemicals. Under defined emergency conditions, the NRA can also issue "emergency use" permits, and can approve the use of agvet chemicals for minor uses that do not normally appear on product labels, and would otherwise be illegal.

The Existing Chemicals Review Program of the NRA reviews registered agvet chemical products to ensure that they meet contemporary standards for efficacy, safety and health, and pose no undue risk to the environment or trade. Recently reviewed chemicals include atrazine, metham sodium, endosulfan and ethylene dibromide, and certain changes to their registration and labelling are being implemented. Several other chemicals are currently under review. The Special Review Program allows the NRA to review registered agvet products if there are any special issues arising that may alter the terms of their original registration.

Current challenges to the NRA include the management of insecticide and weed resistance, particularly in relation to the regulation of genes expressing insecticides and herbicide tolerance.

Specific guidelines for the registration of microbiological products are currently being reviewed. Issues relating to the release of microbial organisms into existing agricultural Systems and environments require considered risk assessment prior to any approval. Macrobiological control agents are specifically excluded from regulation by the NRA. They may, however, be regulated under other pieces of legislation.
Ce document est protégé par la loi sur le droit d'auteur. L'utilisation des services d'Érudit (y compris la reproduction) est assujettie à sa politique d'utilisation que vous pouvez consulter en ligne.

https://apropos.erudit.org/fr/usagers/politique-dutilisation/ 


\title{
Regulation of Microbial Organisms in Australia - A Technical Overview -
}

\author{
Graeme Barden
}

National Registration Authority for Agricultural and Veterinary Chemicals PO Box E240, Kingston ACT 2604, Australia

\begin{abstract}
The National Registration Authority for Agricultural and Veterinary Chemicals (NRA) is the regulatory body responsible for the coordinated registration, regulation and review of agricultural and veterinary (agvet) chemicals up to and including the point of retail sale. This role is defined by the Agvet Code, 1994. Each of Australia's eight states and territories retains its own jurisdictional controls over the use of agricultural and veterinary products.
\end{abstract}

The NRA may issue permits to exercise control over research agricultural and veterinary (agvet) chemicals. Under defined emergency conditions, the NRA can also issue "emergency use" permits, and can approve the use of agvet chemicals for minor uses that do not normally appear on product labels, and would otherwise be illegal.

The Existing Chemicals Review Program of the NRA reviews registered agvet chemical products to ensure that they meet contemporary standards for efficacy, safety and health, and pose no undue risk to the environment or trade. Recently reviewed chemicals include atrazine, metham sodium, endosulfan and ethylene dibromide, and certain changes to their registration and labelling are being implemented. Several other chemicals are currently under review. The Special Review Program allows the NRA to review registered agvet products if there are any special issues arising that may alter the terms of their original registration.

Current challenges to the NRA include the management of insecticide and weed resistance, particularly in relation to the regulation of genes expressing insecticides and herbicide tolerance.

Specific guidelines for the registration of microbiological products are currently being reviewed. Issues relating to the release of microbial organisms into existing agricultural systems and environments require considered risk assessment prior to any approval. Macrobiological control agents are specifically excluded from regulation by the NRA. They may, however, be regulated under other pieces of legislation.

\section{THE NATIONAL REGISTRATION SCHEME}

\section{Scope:}

The Scheme encompasses all herbicides, insecticides and fungicides used in agriculture.

Adjuvants, crop markers, dairy cleansers for on-farm use, marine antifoulants, timber preservatives, insect repellents for use on humans, swimming pool disinfectants and algaecides, and household and home garden products for pest and weed control have been deemed to be agricultural chemical products. Some pest traps and barriers using chemical attractants also require registration. 
Certain products are specifically exempted from registration. These include, but are not limited to:

- Silage inoculants based on bacteria, enzymes or both

- The nematode Deladenus siricidicola for the control of Sirex spp. in pine plantations

- Any predatory insect or mite or macroscopic parasite.

Whether or not they fall under the scope of the Agvet Code, microbial products may also be examined under other schemes or legislation, such as:

- the Guidelines of the Genetic Manipulation Advisory Committee (GMAC)

- the Quarantine Act 1908

- the Wildlife Protection (Regulation of Exports and Imports) Act 1982

- the Biological Control Act 1984

In addition to the registration of end use products, active constituents must be approved or specifically exempted by the NRA either before, or at the same time, as the product is registered.

Variations to the formulation of a currently registered product must also be approved, as must any proposed new patterns of use, new claims and new labels. The Agvet Code requires the NRA to complete its assessments within statutory timeframes, which vary in length according to potential risks associated with a product.

\section{Assessment and Registration:}

Technical information on the product's chemistry (or biology) and manufacture, toxicology, metabolism and toxicokinetics, residues, occupational health and safety, environmental effects and efficacy must be provided. In addition, information on any adverse implications for overseas trade resulting from residues of the product or active constituent is required. For less complex applications, substantial data may not be required but the same criteria need to be considered.

In evaluating an application, specialist staff from within the NRA examine details of a product's (and active con- stituent's) chemistry (or biology) and manufacture, residues and any adverse implications for trade.

In addition, the NRA may seek specialist advice from outside agencies:

- The Commonwealth Department of Health and Family Services evaluates toxicology data submitted by applicants to determine any health risk to the community, and establishes health related end points. Under poisons legislation, consideration is also given to poisons scheduling and first aid instructions for the product.

- The Environment Protection Group of Environment Australia evaluates the environmental implications of products and active constituents and recommends measures to avoid or minimise adverse environmental effects.

- The National Occupational Health and Safety Commission (NOHSC) assesses data relating to occupational health and safety. NOHSC conducts occupational health and safety assessments to ensure that any risks arising out of worker exposure to chemical products are minimised. NOHSC and the Department of Health and Family Services jointly advise the NRA about First Aid and Safety Directions and protective equipment requirements.

- Advice on efficacy and crop safety may be sought from State Departments of Agriculture, and, in some cases, State environmental authorities. Where expertise is not available from within the State departments, advice from independent reviewers may be sought.

- There may also be consultation with other State and Commonwealth agencies and a range of expert panels or committees that provide advice to the NRA (e.g. NHMRC Working Party on Antibiotics, Genetic Manipulation Advisory Committee, Australian Quarantine and Inspection Service, Australian National Parks and Wildlife Service, animal welfare authorities).

When a product proposed for registration contains a new active for use on 
a food crop or animal, the NRA publishes a Public Release Summary. This allows members of the public and relevant industry bodies an opportunity to raise matters of concern about human, animal and environmental safety, efficacy, and trade. All submissions are considered before the labelling of the product is finalised and a final decision to determine the application is made.

\section{THE NATIONAL PERMITS SCHEME}

The NRA also administers the National Permit Scheme for situations where it is necessary to use an unregistered product or a registered product in an unapproved manner. Permits, however, are not a way of circumventing the normal registration process for agvet chemical products. Permits may be issued to cover:

- Emergencies such as outbreaks of contagious disease or exotic pests (e.g., Papaya fruit fly and fire blight) for which no registered product exists (off-label permit);

- Minor use i.e., use of a product on a crop or animal grown on a small scale (off-label permit); and

- Research on agvet chemical products, which can involve use of unregistered products to generate data needed for registration (trial permit).

Each Australian State has different 'control of use' laws. Some States allow registered products to be used in ways that differ from the label, without requiring a permit.

\section{NRA REVIEW OF REGISTRATION}

Registration of agvet chemicals is not indefinite. The NRA is required under legislation to conduct systematic reviews of registered Agvet chemicals to ensure that they meet contemporary regulatory standards. As new scientific data become available, the NRA reas- sesses older chemicals for their possible short and long term harmful effects on human health, occupational health and safety, the environment, efficacy and implications for trade.

These reviews occur under the Existing Chemicals Review Program. Chemicals for review are nominated by the public and prioritised. Reviews involve a thorough re-assessment of data available since the chemical was first registered, and follows a call in of all available data held by the registrants.

A Special Review Program also allows the NRA to immediately review chemicals if there are any special issues arising that may alter the terms of their original registration, causing the registration(s) to be reconsidered. For example, the use of glyphosate in aquatic situations was reviewed as part of this program when it was suspected that the surfactants in products containing this active could pose an unacceptable risk to aquatic organisms. Changes to registration and label updates resulting from this review have recently been completed.

\section{DATA REQUIREMENTS FOR REGISTRATION OF MICROBIAL PRODUCTS}

The NRA has published data requirements for the registration of agvet chemical products. These requirements are mostly directed towards "conventional" chemical products. The NRA recognises the need for separate and specific guidelines for biologically derived products falling under the definition of agvet products. To this end, guidelines were produced in 1994. These guidelines are currently being revised to meet the issues raised by new technologies (e.g., transgenes). However, microbial products are reviewed in very much the same way, using similar criteria, to conventional chemical products.

\section{Biology}

In place of chemical details, data on biological properties of the organism 
are required, as well as end use product details. Some of those properties requiring description include:

- Full taxonomic description, including strain and serotype

- Notification if the organism has been genetically modified

- Geographic origin and natural occurrence of the organism

- Target specificity and host range

- Taxonomic relationship to existing pathogens of crops, vertebrate or non-target invertebrate species

- Site of infection, mode of action and of entry into the host

- Transmissibility and persistence of the organism under different climatic conditions

- Impact of possible mutation or reversion to a pest status

- Pathogenicity to target host species

- Infective dose level

- Genetic stability under environmental conditions (GMOs only)

- Life cycle and growth characteristics

- Infectivity and pathogenicity to humans, non-target animals and plants

\section{Toxicology}

It should be established that the active agent is not a known pathogen of man or other mammals, and that the preparation does not contain pathogens or mutants as contaminants. Also, it must be demonstrated that the active agent will not to be likely to undergo reversions or mutations of pathogenic importance. Primary toxicology data for an active agent and end use product include:

- Acute infectivity: intravenous (bacteria and viruses); intraperitoneal (fungi and protozoa); intracerebral (neurotropic agents)

- Acute oral, dermal and inhalation toxicity

- Eye and skin irritation

- Skin sensitisation
- Genotoxicity (on appropriate extracts)

- Short term repeat dose studies (route depending on likely source(s) of human exposure)

Supplementary toxicological data may be required, depending on indications of toxin production, significant signs of infectivity, or unusual persistence of the microbial pesticide.

- Subchronic toxicity

- Developmental studies

- Reproduction studies

- Immunotoxicity (for viruses)

_ Additional genotoxicity

\section{Residues}

Residue data are not generally necessary for microbial agents. However, applicants must provide reasoned, scientific argument. The NRA will consider exemption from the need for a Maximum Residue Limit on a case by case basis. Residue data will be required where toxicology data indicate adverse effects of the organism or toxins produced by the organism on human health. Even when a known pathogen is not involved, there may still be a need for determining the presence of biologically active or inactive substances in food. To this end, the Australian and New Zealand Food Authority (ANZFA) is involved in the determination of the need for MRLs.

\section{Occupational Health and Safety}

General data requirements for chemical products apply equally to microbiological products. Consideration also needs to be given to other hazards involved in the production and handling biological products (e.g., liquid nitrogen). The possibility of post application release of toxins requires the consideration of re-entry periods and the handling of treated produce.

\section{Environment}

The Australian environment is highly diverse and unique. Many of our flora and fauna have evolved in isolation from pests and predators. As such, Australian ecosystems may be particularly 
sensitive to the introduction of exotic organisms. Key issues to be addressed include:

- Population growth characteristics

- Strain stability (purity)

- Survival in niche or host environments after release into the environment

- Pathogenicity and infectivity to nontarget organisms

- Indigenous or exotic organism

\section{Efficacy}

Efficacy data is required for all microbial products, due to variability that can arise due to simple changes in manufacture. Data should be gathered over two seasons in representative areas in at least two states where the product is intended to be used. Variations on this theme are permitted, on a case by case by case basis. To ensure product efficacy in the field, all microbial products are "Date-controlled", in that labels for these products must bear an expiry date, after which supply and use is illegal.

\section{EXAMPLES OF AUSTRALIAN EXPERIENCE WITH MICROBIAL PRODUCTS}

\section{Bacillus thuringiensis (various strains or subspecies)}

Bt sprays have become principal control tools, particularly to 'organic' food producers. Applications to the NRA for Bacillus thuringiensis $(\mathrm{Bt})$ products comprise a large proportion of applications received by the NRA for registration of microbial products. Unless an application involves a new subspecies, strain, variety or source of $\mathrm{Bt}$, reduced data packages are generally required. Usually the following areas need to be addressed:

- Details of the manufacturing process (including TGAC source)

- Description of quality control measures

- Batch consistency

- Stability and shelf life

\section{Bt genes (Ingard cotton)}

Currently in Australia, there is only one registered product based on transgenes. Rather than register plants themselves, the NRA has registered the gene construct known as Ingard. Given the novelty of this product to Australia, the NRA required a thorough evaluation of data covering most of the requirements for a new chemical. This involved the NRA seeking public submissions based on a Public Release Summary.

One of the major issues for the evaluation of the registration application was whether or not the ongoing $\mathrm{Bt}$ endotoxin expression by cotton plants could provide selective pressure towards the development of resistance to Bt generally by Helicoverpa spp. (heliothis). Such an event could have negative impact on conventional spray use, particularly to organic growers. Heliothine species in Australia and the USA show significantly different responses to pesticide application. To date, field data suggest that in the two countries, response of heliothine pests to $\mathrm{Bt}$ cotton is divergent. This leads to the suggestion that trials specific to the intended country of use will remain vital to robust registration decisions.

The solution presented (to resistance development) was to provide areas of refuge (or sacrifice) crop that would remain unsprayed. Adults produced from these refuges would provide a diluting factor for resistant individuals developing from within the Ingard crop. The type of refuge crop is limited by type and size. This is based on data indicating 'productiveness' of refuge crops, in terms of ability to produce sufficient numbers of susceptible adults. To add robustness to the strategy, the NRA's decision to register Ingard was conditional on the planting area being in proportion to the total cotton cropping area in any given year, thereby offering further potential refuge for $\mathrm{Bt}$ susceptible individuals. Annual incremental increases in the approved area are considered appropriate, subject to provision of data confirming product efficacy and a lack of resistance development. In making this decision to stage the introduction of Bt cotton, the NRA 
considered advice provided by the Genetic Manipulation Advisory Committee (GMAC). Finally, Bt cotton plantings and conventional chemical use must fit into the current Insecticide Resistance Management Strategy for Cotton. This strategy calls for rotational use of chemicals (and microbials) through each cropping season.

To date there have been savings in chemical usage over Bt cotton, compared to conventional cotton. This has certain obvious benefits in terms of beneficial insects in the crop, as well as environment benefits, through reduced chemical usage. However, 'plant pesticides' will, in most cases, be scrutinised in their ability to compliment existing integrated pest management strategies, and also in their ability to be grown under their own IPM strategy as required.

Another significant concern was the possibility of gene escape through outcrossing with native Gossypium spp. and the possibility of commercial cotton becoming a feral pest. By assessment of native species' distribution, and data gathered from attempts to produce viable offspring from various backcrossing trials, the NRA was able to include in its decision a restricted geographical planting range. This range provides for confident management of the risk of gene escape. There do exist certain regions of Australia that, while being potentially suitable for cotton production, contain native Gossypium spp. apparently more closely related to commercial cotton. Approval for use of $\mathrm{Bt}$ cotton in these areas will require that the registrant address these issues in specific detail.

The introduction of transgenes to an environment provides for two great concerns; damage to existing IPM strategies and the loss of "conventional" spray technologies, and damage to the environment through the development of feral species with built in defence against those species that might otherwise control the plants bearing them. The opportunity to 'stack' genes encoding for different pesticidal proteins may offer greater confidence in resistance management.

\section{Capillaria hepatica}

This liver parasite was proposed some years ago for the control of mouse plagues. Due to potential pathogenicity of the parasite to humans, this microbial control agent was not approved.

\section{Rabbit calicivirus}

The rabbit has been a major pest to Australian agriculture for many decades, through damage to soil structure and physical injury to livestock, both phenomena due to the rabbits' system of burrows, or warrens. The rabbit has been a competitor for food resources for livestock and native fauna, and has played a significant role in floral damage and land degradation. Physical control methods have included mustering rabbits into fenced areas for clubbing and destruction of burrows by ripping with machinery and use of explosive charges. Various fumigation methods have also been employed. In the 1950s, the myxomatosis ("myxo") virus was 'released'. The virus was initially effective, but over time, rabbit numbers have increased and "myxo" is generally ineffective as a population control measure.

In 1996, the NRA approved the release of another exotic organism, generally called the rabbit calicivirus (RCD), or rabbit haemorrhagic disease (RHD). The NRA required the applicant to demonstrate, amongst other things, that release of this new virus (to Australia) would not cause undue risk to native ecosystems. Non-target infectivity was also considered critically important. Further, the effect of rabbit population decimation, if achieved, on predatorprey complexes needed to be addressed. Two other exotic pests, the fox and the domestic cat are known to include rabbits as a significant component of the diets of these two species. In addition, consideration was given to possible mutations that might give rise to a pathogen of humans, native fauna and domestic pets. Clearly then, the effects of exotic microbial agents can be widespread, and not necessarily be direct. Consequently, locally relevant environmental studies on microbial products were required. 


\section{Herbicide tolerant crops}

The NRA does not currently have the regulatory authority to regulate transgenes expressing herbicide tolerance. However, the NRA is required to assess new use patterns for existing chemicals on herbicide tolerant crops. The main benefit given for herbicide tolerant crops is that they will provide growers with a greater flexibility in spray timings, being no longer constrained by the usual detriment of spray drift and crop growth stage. The implications of introducing such transgenes are considered by GMAC, which receives submissions from proponents before any trail or commercial release is undertaken.

The use of herbicide tolerant or herbicide resistant crops has the potential to change crop management and the patterns of herbicide use in cropping systems. Sustainable cropping systems need to be developed so that overall chemical burden is not increased because of the emergence of resistant weeds resulting from inappropriate use of herbicides. Weed management strategies may need to be proposed to address these issues. Gross shifts in herbicide usage could have significant negative impacts on the environment. An example is that of triazine tolerant canola. The NRA has reviewed data to support ongoing registration of atrazine products. Issues raised included contamination of surface and ground water. Should triazine tolerant canola be grown significantly in Australia, increase in atrazine usage could have the potential to cause contamination of surface and ground water in Australia.

MRLs are usually set according to toxicological risks, and good agricultural practice (GAP). GAP provides, among other things, for spraying with chemicals only as often as required to achieve the required level of control. MRLs are also based on defined use patterns. For example, if a herbicide intolerant crop is sprayed between rows only, an MRL will be set, accounting for that lower level of crop contact with the herbicide. With herbicide tolerant crops able to withstand directed sprays, and assuming a herbicide of low toxicological consequence, it may possible that registrants of chemical products will seek to have MRLs set at higher levels. Regulators will need to firmly address the acceptability and meaning of residue limits. What is the difference between apparently safe residue levels, and agriculturally 'appropriate' residue levels?

Of course, these questions arise whether the crop has been developed using recombinant DNA technology to genetically modify the crop, or has been conventionally bred. They relate primarily to the changes in herbicide use arising from introduction of herbicide tolerant crops.

As with 'plant pesticides', the introduction of herbicide tolerant crops introduces further risk to the development of weed tolerance, or even resistance, developing through increased exposure to herbicide. Given that the NRA cannot directly regulate herbicide tolerance genes, it has a limited capacity to assist in the prevention of herbicide resistance in weeds growing under herbicide tolerant crops. Indirectly, the NRA already has a tool in this regard. Herbicide (and fungicide) product labels are required to bear chemical 'group' symbols (based on mode of action of the chemical) on their main panels, with supplementary information appearing elsewhere. By rotating chemical use through different groups where-ever possible, users may be able to assist in the prevention of herbicide resistance development in weeds. A possible difficulty with this strategy might be the marketing of seed and chemical product as a package deal. Cheaper chemicals may prove attractive to growers in the short term, however the long term cost through herbicide resistance in weeds may be considerable. By assisting in the development of weed resistance management strategies, chemical companies may be able to help protect the technology now being commercialised. 


\section{CONCLUSIONS}

Microbial organisms have the potential to augment or replace some existing chemical control techniques. While some of the risks associated with chemicals may be avoided with the use of microbial products, other risks are introduced. These risks relate particularly to the introduction of exotic organisms to ecosystems, and to the potential effects on existing integrated pest management strategies.

Australia's experience with microbial products has highlighted the need for local data to support registration applications. These data most readily pertain to product efficacy and environmental risk.

Australia either has, or is developing, policies and regulatory frameworks for microbial (including genetically modified) organisms. While information exchange between regulatory bodies of different countries may be desirable, considerable discussion will be required to harmonise requirements and standards.
Two questions:

- As the number of crops expressing a particular pesticide increases, will regulatory mechanisms be faced with the question of how, for example, a Bt cotton resistance management plan will fit in with a plan for Bt chickpeas? Equally, will separate cropping industries be able to cooperate to enable resistance management regionally, rather than simply within an individual cropping industry?

- 'Organic' growers often use microbial products as pest control agents, without affecting their 'organic' status. As microbes are either genetically modified, or have their genes inserted into crops, how will this status be affected? 